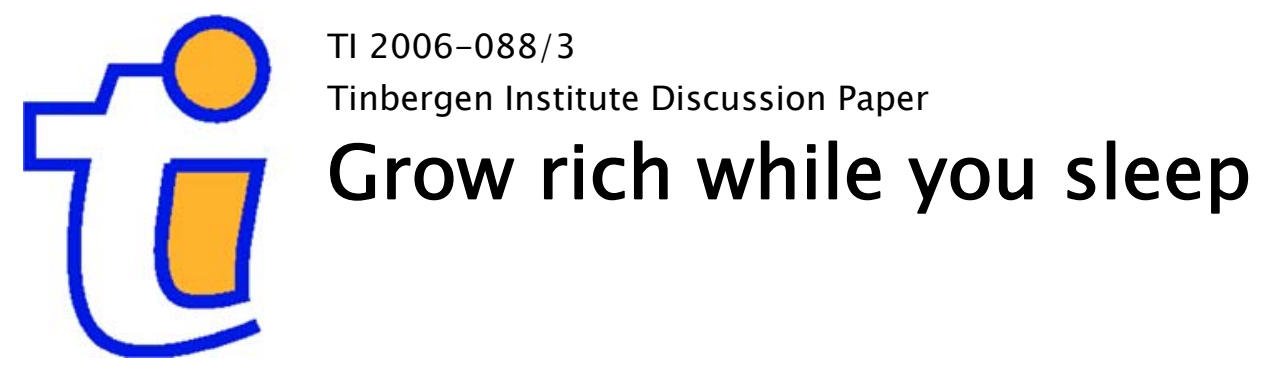

Pieter Gautier

Bas van der Klaauw

Vrije Universiteit Amsterdam, and Tinbergen Institute. 


\section{Tinbergen Institute}

The Tinbergen Institute is the institute for economic research of the Erasmus Universiteit Rotterdam, Universiteit van Amsterdam, and Vrije Universiteit Amsterdam.

Tinbergen Institute Amsterdam

Roetersstraat 31

1018 WB Amsterdam

The Netherlands

Tel.: $\quad+31(0) 205513500$

Fax: $\quad+31(0) 205513555$

Tinbergen Institute Rotterdam

Burg. Oudlaan 50

3062 PA Rotterdam

The Netherlands

Tel.: $\quad+31(0) 104088900$

Fax: $\quad+31(0) 104089031$

Most TI discussion papers can be downloaded at http:/ /www.tinbergen.nl. 


\title{
Grow Rich While you Sleep: SELECTION IN EXPERIMENTS WITH VOLUNTARY PARTICIPATION*
}

\author{
Pieter A. Gautier ${ }^{\dagger}$ \\ Vrije Universiteit Amsterdam and Tinbergen Institute \\ Bas van der Klaauw \\ Vrije Universiteit Amsterdam and Tinbergen Institute
}

October 2006

\begin{abstract}
We use data from a promotion campaign of NH-Hoteles to study self-selection of participants in a gift-exchange experiment. The promotion campaign allowed guests to pay any non negative amount of money for a stay in one of 36 hotels in Belgium and the Netherlands. The data allow us to distinguish between 'regular guests', who booked prior to the announcement of the promotion campaign and guests who booked after the campaign was announced. During the promotion campaign we varied the posted price of a room that was communicated to the guests. Only the regular guests respond to the exogenous variation in the posted price and they pay substantially more on average. This different behavior cannot be explained by differences in satisfaction or observed compositional differences between both groups. We argue that the promotion campaign mainly attracted individuals who find it relatively unimportant to be viewed of as prosocial.
\end{abstract}

${ }^{*}$ We thank Huib Voorn and Elisabeth Stevens of NH-hoteles for using their data and Armin Falk, Evgenia Motchenkova, Thomas Palfrey and seminar participants at the Vrije Universiteit Amsterdam for useful discussions.

${ }^{\dagger}$ Department of Economics, Vrije Universiteit Amsterdam, De Boelelaan 1105, 1081 HV Amsterdam, $<$ pgautier@feweb.vu.nl>. Gautier acknowledges financial support from NWO through a VIDI grant

${ }_{\ddagger}^{\ddagger}$ Department of Economics, Vrije Universiteit Amsterdam, De Boelelaan 1105, 1081 HV Amsterdam, $<$ bklaauw@feweb.vu.nl>. 


\section{Introduction}

In the weekend of December 16-18, 2005, NH-Hoteles had a promotion activity in all their 36 hotels in Belgium and the Netherlands. When checking out, the hotel guests could decide themselves how much they wanted to pay for their stay (including the breakfast). Paying nothing was also allowed. Before the hotel guests actually made their payment, they had to fill in a short questionnaire about their stay. On this questionnaire, the "usual" price for a stay in the hotel was announced. On our request, NH-Hoteles raised this posted price with 20 euros on the first day of the promotion weekend. We exploit this exogenous variation to investigate the causal effect of the posted price on the paid price and the satisfaction of guests.

The promotion activity was announced 4 weeks before the weekend in which it took place. About $6 \%$ of the hotel guests in our data set had already booked prior to the announcement of the promotion activity. These hotel guests could also decide their own price. Since the promotion activity took place in a weekend, the vast majority of visitors were non-business people. The main goal of this paper is to compare the behavior of these "regular guests" who participated involuntary with the behavior of individuals who participated voluntary because they booked a hotel after the promotion activity was announced. This allows us to investigate the consequences of self-selection in (field) experiments. Recently (laboratory) experiments have been criticized for their lack of external validity by Harrison and List (2004) and List and Levitt (2005) amongst others and they mention self-selection as one of the main problems.

The setup of the promotion activity has strong similarities with gift-exchange and tipping games and to a lesser extent with dictator and trust games. ${ }^{1}$ These type of games are often evaluated in the laboratory. To our knowledge there exists no laboratory experiments on prosocial behavior for such a large group where the stakes are so high. There is some evidence that agents tend to behave more selfish in the field than in laboratory environments. ${ }^{2}$ We find however that even in this non-laboratory setting the guests donate substantial amounts. Gneezy and List (2006) also study a gift-exchange experiment in the field. They mainly focus on the representativeness of the environment and argue that great care should be taken when making inference from laboratory experiments to the field. Our concerns on the external validity of experiments are based on the composition of the participants rather than the institutional environment.

\footnotetext{
${ }^{1}$ There is a huge literature on dictator games, see Camerer (2003) for an overview. Fehr, Kirchsteiger and Riedl (1998) is an example of a gift exchange experiment while Ruffle (1996) and Azar (2002) discuss tipping games.

${ }^{2}$ See List and Levitt (2005). On the other hand, Falk (2004) gives field evidence that donators to a charity fund pay more if they receive a small gift (i.e. a postcard).
} 
Laboratory experiments usually have voluntary participation and therefore are likely to attract a selective group of individuals. Participants are often students, but selection into laboratory experiments can also be on unobserved characteristics. For example, altruistic individuals may be less likely to participate in experiments, where participants can signal prosocial behavior at a cost, than egoistic individuals. ${ }^{3}$ For experiments that aim to mimic real-world markets, it is desirable that the participants are representative for the market participants. For example, in complicated auctions the market participants are typically experts in the field while participants in laboratory experiments are not. So the problem is not selectivity persé but the fact that participants in a laboratory experiment may behave fundamentally different than the relevant group they are supposed to represent. Also in many field experiments participation is voluntary, so the selection problems we highlight in this paper may be relevant for field experiments.

To illustrate the selectivity problem in gift-exchange experiments consider the following example. Suppose workers vary in the way they value money and the desire to be viewed of as a prosocial individual, see Bénabou and Tirole (2006), and that they can take two routes from the railway station to their office: a long route with few beggars and a short route with many beggars. A researcher who is interested in how much people are in general willing to donate to beggars underestimates the donations if he looks at the average donation that a beggar receives. The reason for this is that in the researchers sample the most selfish workers, who choose the short route with the beggars, are overrepresented. The more altruistic workers will, when being face-to-face with a beggar, donate a large sum of money to meet the high social standards imposed on themselves. They are also most likely to take the long route to avoid being forced to make costly signals when meeting a beggar. In order to identify the average willingness to donate for the entire population one would need workers who are not aware of the location of beggars. The regular guests in our experiment play exactly this role.

The main contribution of this paper is that we present evidence that some concerns on self-selection are legitimated. Compared to laboratory experiments our data are relatively rich on explanatory variables, but controlling for these observables does not solve the problem of self-selection. Furthermore, we relate the size of the donations and, more importantly, the response to variations in the posted price to these observables and continue to find different behavior between the regular and the experiment guests.

The paper is organized as follows. Section 2 discusses the design of the experiment. In section 3 we present our main results, section 4 discusses some implications of our results and provides a theoretical background. Finally, section 5 concludes.

\footnotetext{
${ }^{3}$ Lazear, Malmendier and Weber (2005) give evidence that some participants in their experiment were willing to pay money in order to avoid playing a dictator game.
} 


\section{Design of the field experiment}

During the weekend of the promotion activity, NH-Hoteles allowed guests to book a hotel for at most one night. At check-out each hotel guest had to hand in a short questionnaire which they received while checking in. The appendix contains a copy of the questionnaire. This questionnaire stated a usual price for a stay in the hotel, which we refer to as the posted price. This posted price depends on the type of hotel. When actually checking out, the hotel guests handed the completed questionnaire together with their voluntary payment to the receptionist of the hotel, who wrote the amount of the payment on the questionnaire. The questionnaire explicitly stated that the receptionist would ask for a reason if a guest would make a payment of 0 euros. ${ }^{4}$ It is very likely that this increases donations since there exists a lot of evidence that people increase their level of cooperation when they are being watched, e.g. Milinsky, Semman and Krambeck (2002) and Soetevent (2005).

All 36 hotels of NH-Hoteles in Belgium and The Netherlands participated in the promotion activity. The promotion activity was announced in an advertisement campaign using billboards, advertisements in newspapers and magazines, mailings and internet, four weeks prior to the weekend of the promotion activity. The guests who booked via an external travel agent were not allowed to participate. The questionnaire contained a question about how the guests had learned about the promotion activity. A small fraction of the guests were not aware of the promotion activity until the moment they checked in. Most of these individuals had booked already before the start of the promotion campaign. They could also decide how much they wanted to pay for their stay. We call these individuals regular guests and refer to the other guests as experiment guests. The regular guests can be considered to be involuntary participants in a gift-exchange-field experiment while the experiment guests are voluntary participants.

In addition, the questionnaire contained three blocks of questions. The first set of questions involved the gender, age, place of residence and nationality of the guest. The second block contained questions on how often the individual usually stays in hotels and how familiar the guest is with HN-Hoteles. The third block of questions was about the satisfaction with the stay. The guests had to give an over-all grade for the stay and they had to give separate opinions on the quality of the personnel, room and breakfast. Just before this third block of questions concerning the guest's satisfaction, the questionnaire posted the usual price for the stay. On our request this posted price was increased with 20 euros for the first night of the promotion activity. ${ }^{5}$

\footnotetext{
${ }^{4}$ About paying nothing the following text was written on the questionnaire: "What happens if I don't want to pay anything? That's possible, which would mean that you did not like it at all. We will, of course, ask you why you experienced a stay in our hotel worthless".

${ }^{5}$ Two hotels distributed the questionnaires with the increased prices on Saturday and Sunday (and the
} 
In total 5885 guests completed the questionnaires. The non-response rate was less than 1 percent. We deleted 237 questionnaires from our data because either the amount paid or the over-all hotel grade was missing. Furthermore, we excluded 234 questionnaires for which gender or age was missing or the age of the individual was below 16 years old. Finally, we dropped 392 individuals from the data for which we do not know whether they were regular guests or experiment guests. This leaves us with 5022 observations: 301 regular guests and 4721 experiment guests.

Table 1 provides some summary statistics of the data. We observe that regular guests pay on average about twice as much as the experiment guests. This difference cannot be explained by the fact that regular guests stay in different hotels than the experiment guests. The distribution of regular guests and experiment guests over three, four and five-star hotels is roughly the same. Both the fraction of individuals that does not pay anything and that pays less than 10 percent of the usual price is about twice as large among experiment guests as among regular guests. Furthermore, while only 1 percent of the experiment guests pays more than 90 percent of the usual price, about 12 percent of the regular guests pays more than 90 percent of the regular price. The difference in donations is also not due to the fact that the group of regular guests contains more business people who do not pay themselves. Recall that the experiment was held in a weekend with few business travelers. We also have information on whether the guests often stayed in hotels, which is strongly correlated with being a business traveler. Below, we show that controlling for this, the difference remains large. Furthermore, we checked whether the regular guests paid themselves or whether someone else paid for them. We could do this because the hotel records unique custom numbers of their visitors and links this information with, amongst others, who pays the bill. $^{6}$ Within the group of regular guests we have this information for 194 of the customers (64\%). We find that within the group of regular guests, 93\% paid themselves. Those who did not pay themselves paid on average 6 euro less than those who paid themselves but the difference is not significant.

Figure 1 shows kernel estimates for the density function of donations of the experiment guests and the regular guests. Donations are taken as fraction of the posted price on the questionnaires on Saturday and Sunday. Some values are above 1 because some people paid more than this usual price. Most of this occurred on Friday when the posted price was 20 euros above the one on Saturday and Sunday. From the figure it is clear that there is a lot of variation in donations and that regular guests pay more than the experiment guests over the entire distribution.

lower prices on Friday). In one hotel both types of forms were distributed on each day.

${ }^{6}$ The checking of who made the payment had to be done case by case by an employee from NH-Hoteles, therefore this was only done for the group of regular guests. 
These differences cannot be explained by differences in satisfaction about the hotel. The average grade is about 7.3 for both the regular guests and the experiment guests. In Figure 2 we have plotted kernel estimates of the grades. ${ }^{7}$ The density functions of the regular guests and the experiment guests are rather similar. Table 1 shows that there are considerable compositional differences between the two groups. Among the experiment guests the fraction of females is higher. ${ }^{8}$ Furthermore, experiment guests are on average younger and have more often the Dutch nationality. The group of regular guests contains a larger share of individuals who stay often (at least 5 nights per year) in hotels. Finally, the questionnaire provided some room for comments. Both within the group of regular guests and within the group of experiment guests, about $47 \%$ wrote at least three lines of comments.

\section{Results}

\subsection{Donations}

Our main variable of interest is the donation paid by the guests. We already established that the regular guests pay approximately 24 euro more than the experiment guests. However, there are large compositional differences between both groups. In Table 2 we present results from a regression that accounts for observed compositional differences (and for hotel fixed effects). The estimation results show that regular guests pay about 18 euros more than experiment guests with similar observed characteristics and this difference is highly significant. This implies that observed compositional differences can only explain 25 percent of the differences in donations between regular guests and experiment guests. The posted price does not affect donations significantly. In fact, raising the posted price by 20 euros on average only increases a donation by about 0.7 euro. Donations increase with age (until age 81). Guests with the Belgian or Dutch nationality pay significantly less than individuals with other nationalities (also the difference between Dutch and Belgians is significant) and women pay less than men. Surprisingly, whether or not people stay often in hotels does not affect donations.

Obviously, there are unobserved characteristics that cause regular guests to pay more than the experiment guests. But we cannot conclude that the experiment guests behave differently from the regular guests. The regular guests made their hotel reservation expecting to pay the usual price, while the experiment guests booked after they learned about the promotion campaign. The marginal willingness to pay of the regular guests is therefore above the usual

\footnotetext{
${ }^{7}$ The humps are caused by the fact that people typically give whole-number grades.

${ }^{8}$ The questionnaire did not ask if an individual stayed alone in a room or as part of a couple. According to the hotel managers the vast majority were couples. We assume that the person who completed the questionnaire was also the decision maker on the payment.
} 
price of the hotel they are staying in.

Our findings are also in line with Kahneman and Tversky (1979) and Köszegi and Rabin (2006). The latter developed a model with reference dependent preferences where the reference point of an agent is determined by rational expectations and willingness to pay (conditional on purchase) is increasing in expected prices. Furthermore, when making the hotel reservation, some experiment guests did not end up at their first choice because the top hotels were booked full fast. The regular guests could therefore derive a higher utility from staying in the same hotel than the experiment guests. Hence, at this stage we cannot rule out that both regular guests and experiment guests pay a particular fraction of their marginal willingness to pay and then it is not surprising that regular guests pay significantly more.

In Tables 3 and 4 we present the results from separate regressions for the regular guests and the experiment guests. We are mainly interested in the effect of the posted price on the donations made by both types of guests. The first column of the tables shows that regular guests pay significantly more in response to the posted price increase while the experiment guests do not respond to exogenous changes in the posted price. The second column shows that this result remains present after controlling for individual characteristics. A 20 euro increase in the posted price causes the regular guests to increase their payment by about 11.32 euro, which is about $23 \%$ of their average payment. The experiment guests only pay 0.08 euro extra if the posted price is increased by 20 euro. This implies that regular guests not only pay more, but also that they respond differently to changes in the institutional setting than the experiment guests. In Section 4 we return to the implications of this finding.

\subsection{Satisfaction}

Recall from the previous section that regular guests and experiment guests gave on average approximately the same grade for their stay. However, if we account for differences in observed individual characteristics and hotel fixed effects, then regular guests give significantly higher grades (see Table 5). Either they are more satisfied or they respond to the gift of a free room by giving a higher grade as a form of positive reciprocity. If the difference in payments between regular and experiment guests would entirely be driven by satisfaction, then the returns to an additional point (on a ten-point scale) in grades should be around 118 euro. This huge return makes it implausible that differences in satisfaction are the only reason for differences in donations. The posted price has a small negative effect on satisfaction; a 20 euro increase in the posted price reduces the hotel grade by less than $1 \%$ of the average grade. Females give higher grades than males (recall that males paid significantly more). The average satisfaction is increasing in age for individuals older than 21 years. Belgians (and also Dutch) are significantly more satisfied than foreigners. This is surprising 
since Belgians and Dutch pay significantly less than foreigners. The difference in satisfaction between Belgians and Dutch is not significant. Individuals who stay in hotels often, give significantly lower grades.

Again we have performed separate regressions for the regular guests and for the experiment guests. The results of these regressions are presented in Tables 6 and 7 . From the first column of the tables we see that the posted price has a small negative effect on the satisfaction of both the experiment guests and regular guests. Only for the experiment guests this effect is significant (at the 10\%-level). Once we control for observed individual characteristics (see the second column), the posted price no longer significantly affects satisfaction. In both groups females give higher grades than males, older individuals give higher grades (the maximum for regular guests is 66 years and the minimum for experiment guests is 24). Being Dutch has opposite effects in both groups and those who stay often in hotels give lower grades.

The regressions above show that regular guests pay much more, but are only slightly more satisfied with their stay than experiment guests. Furthermore, a higher posted price increases the donations of regular guests, but this cannot be caused by an increased satisfaction as the posted price does not affect satisfaction. This raises the question if a higher level of satisfaction is associated with higher donations. The third columns of Tables 3 and 4 show that indeed more satisfied guests donate more. Regular guests who are one point more satisfied pay on average 4.7 euro extra, which is $9.6 \%$ of the average donation. The returns to an additional point in satisfaction is lower for the experiment guests both in absolute and relative terms. Experiment guests who are one point more satisfied pay on average 1.7 euro extra, which is $6.8 \%$ of their average donation. It should be stressed that these results should not be interpreted as causal as the donation and level of satisfaction are jointly determined by the hotel guests. Therefore, these regressions suffer from endogeneity problems. For the regular guests the effect of the posted price on donations remains unaffected after including the level of satisfaction as additional regressor. This suggests again that the effect of the posted price on donations cannot be explained by an increased level of satisfaction. Consequently, the difference in payment strategies between the regular guests and the experiment guests cannot be attributed to differences in levels of satisfaction.

To further investigate the relation between payment behavior and satisfaction, we explore data on how guests experience different aspects of the hotel. The questionnaire asked the hotel guests to rate the personnel, room and breakfast separately. The rating occurred in 4 categories $(i)$ bad, (ii) insufficient, (iii) good, or (iv) very good. Only very few hotel guests state that something is bad and therefore we combine this category with the insufficient category. We have constructed dummy variables that indicate if a guest valuates some aspect as either good or very good. Only $5 \%$ of the hotel guests finds the personnel bad or 
insufficient and this fraction is $17 \%$ for the room and $7 \%$ for the breakfast. The fraction of hotel guests that considers the personnel good is $72 \%$ while it is $68 \%$ for the room and $64 \%$ for the breakfast. $23 \%$ of the participants rates the personnel very good, for the room and the breakfast those fractions are $15 \%$ and $29 \%$ respectively.

The third columns of Tables 6 and 7 show how the hotel grade depends on how the guests evaluate the personnel, room and breakfast. Both for the experiment guests and the regular guests the evaluation of the room has the largest impact on the overall satisfaction and the breakfast has the smallest impact. For the regular guests the personnel is considered to be almost as important as the room, while for the experiment guests the evaluation of the room is significantly more important.

In the fourth columns of Tables 3 and 4 we have replaced the overall hotel grade with the evaluations of the personnel, room and breakfast in the donations regressions. For the regular guests, the small sample makes the standard errors large. Even though the coefficients are not significant, there is some indication that regular guests who valuate the room as good or very good give higher donations, while this is less the case for breakfast and not at all for the personnel. For the experiment guests an increase in the valuation of any of the three components from bad or insufficient to good or very good raises the donation. However, the magnitude at which donations increase does not vary much between personnel, room and breakfast.

\subsection{Comments about the stay}

The questionnaire offered some room for making comments. As mentioned in the previous section both in the group of regular guests and experiment guests, slightly less than $50 \%$ used this space to add at least 3 lines of substantial comments. Adding comments could be a justification for paying a lower donation or even a substitute for a monetary payment. In the latter case the guest provides information instead of money. On the other hand, hotel guests who make a large donation possibly perceive that this gives them the right to comment on the hotel. In the first columns of Tables 8 and 9 we regress whether or not a guest made comments on the individual characteristics and the hotel fixed effects. For regular guests none of the individual characteristics has a significant impact. For the experiment guest we find that individuals around age 45, women, persons with a Dutch nationality, and individuals who often stay in hotels are most likely to write comments. In the second column of the tables we have added the hotel grade as additional variable. This shows that both regular guests and experiment guests are more likely to comment if they are less satisfied. The third and fourth columns show that the size of the donation does not affect the likelihood of commenting. The main conclusion is thus that hotel guests mainly use the space on the questionnaire to express a negative opinion about the hotel and that 
the size of the donation is unrelated to making comments. The first coincides with the fact that most comments indeed involved possible improvements to the hotel.

\section{Explanations and implications of our results}

A straightforward explanation for the difference in donations between the regular and experiment guests would be that the regular guests are involved in a repeated game, while the experiment guests play a one-shot game. In that case the donations of the regular guests could be interpreted as investments in a good relation with (the personnel of) NH-hoteles. Recall that the questionnaire asked whether or not the hotel guests stayed in an NH hotel before. About $47 \%$ of the regular guests and $33 \%$ of the experiment guests stayed in an NH hotel before. For both the regular guests and the experiment guests, those who stayed in an $\mathrm{NH}$ hotel before donate on average about $5 \%$ more. We have repeated the earlier analyses on the donations for guests who never stayed in a NH hotel before. Most likely these are all hotel guests playing one-shot games. For the experiment guests a 20 euro higher posted price decreases average donations with 0.44 euro, while for the regular guests it increases average donations with 4.96 euro. The latter estimate is significant at a 10\% level. Furthermore, the experiment guests, who stayed in NH hotels before, only increase their donation on average by 1.10 euro in response to a 20 euro higher posted price and this estimate is insignificant. So even if we stratify our groups of hotel guests further by experience with NH hotels, we find the same results as before. This implies that the idea that regular guests play repeated games and experiment guests play a one-shot game cannot explain the behavioral differences between both groups.

The fact that many individuals pay substantial amounts of money to the hotels is in line with the enormous amount of evidence from dictator, gift-exchange, public-good, and trust games in the laboratory. Those results suggest that individuals do not only care about monetary rewards because if they would, they would pay nothing in the final stage of the game. Our paper contributes to this literature by extending it to a non-undergraduate student population in a real world setting. Moreover, our large sample size allowed us to show how donations vary by gender, nationality and age. We find that people are very heterogeneous in terms of their donations. The evidence that many people care about more than their own monetary pay-offs resulted in a booming behavioral literature and many concepts from psychology were introduced in economics, like fairness, reciprocity, social norms and trust. Camerer, Loewenstein and Rabin (2003) provide a selection of the most important contributions in this field. More recently, there is a growing literature that explains the experimental findings without abandoning the standard neo-classical methodology which is based on consistent preferences and equilibrium, see for a recent contribution Bénabou 
and Tirole (2006). Such an approach has the advantage that theory is not replaced by a collection of anecdotes that only holds in a very specific context.

The substantial donations can also be explained by a standard reputation model where the hotel guests signal that they are wealthy or generous to either the personnel, the persons they shared a room with or themselves. As mentioned before, there is experimental evidence that cooperation increases if agents know or perceive that they are being observed. Soetevent (2005) shows that in church people donate more in an open basket than in a closed basket. Bateson, Nettle and Roberts (2006) show that even photocopied images of a pair of eyes increase contributions to an honesty box used to collect coffee money in a university coffee room. Compared to having an image of flowers, people paid on average 2.76 times as much when the image contained the photocopied eyes. In our experiment the hotel guests paid non-anonymously to the personnel, which explains the high average donations. If even very weak subconscious cues like photocopied eyes make people act more altruistic, it is likely that in many anonymous experiments there might have been small cues that gave people the perception that they were being observed. If this is correct, the experimental evidence on reciprocity can also be explained by standard reputation concerns. Given that most hotel guests have a desire to donate money after a stay in a good hotel, it is not puzzling why a profit maximizing hotel chain chooses a promotion campaign like this. The management of NH-Hoteles informed us that total profits in this weekend were higher than profits in the same weekend a year earlier. This is because there is usually excess capacity in the week before Christmas while during the promotion activity most hotels were fully booked and the marginal costs of a booked room are low.

The regular guests booked the hotel before the promotion activity was announced and therefore their marginal willingness to pay exceeds the usual price. If hotel guests pay a fraction of their marginal willingness to pay, this explains the difference in average donations between regular guests and experiment guests. It can, however, not explain why only the regular guests respond to exogenous variation in the posted price. Explaining the latter finding requires that prices only affect the marginal willingness to pay of the regular guests. There exists an older literature that allows prices to enter directly into the utility function (see Kalman, 1968). This applies in particular to goods with a snob appeal but it could also reflect that consumers judge quality by price. An alternative reason why prices affect utility is that prices influence an individual's reference point (e.g. Kahneman and Tversky, 1974; Köszegi and Rabin, 2006). Using non-experimental data on equilibrium prices and quantities, it is impossible to identify supply and demand from each other and thus to investigate if prices directly affect utility. Ariely, Köszegi, Mazar, Shampan'er (2004) report evidence based on experimental data that reservation prices depend on the distribution of prices. The exogenous price variation used in this paper had a negligible effect on the valuation of both 
experiment and regular guests. At the same time it has a big impact on the amount of money that the regular guests pay while it has a negligible and insignificant effect on the amount that the experiment guests pay. Explaining the latter finding with reference point utility requires that the posted prices are outside the range of possible donations for the experiment guests while prices are in the increasing part of the utility function for the regular guests.

The larger donations and the response to the exogenous price variation of the involuntary participating regular guests are also in line with the sorting argument of List and Levitt (2005) and Bénabou and Tirole (2006). The latter paper studies the interaction between social motives, material incentives and the economic environment. People can engage in costly prosocial behavior to signal their type to others or to themselves. Individuals who think of themselves or want to be thought of as very generous and prosocial are less likely to voluntary participate in the gift-exchange field experiment because it requires a relatively large sum of money to confirm those expectations. ${ }^{9}$ The main implication of our results is therefore that we have to be careful in extrapolating conclusions that are based on an experimental setting with voluntary participation without correcting for self selection.

\section{$5 \quad$ Final remarks}

We studied a field experiment of a gift-exchange game where the gift is a stay in a 3-5 star hotel in the Netherlands or Belgium. The data allowed us to distinguish between voluntary and involuntary participants. We find that only the involuntary participants respond to an exogenous increase in the posted price of the gift by paying more for their stay. We explain these behavioral differences from differences in the degree that individuals are prosocial. Individuals who consider themselves as highly prosocial should give higher donations to conform and signal their type to others and themselves. Therefore, highly prosocial individuals gain less from the gift-exchange game than individuals who put more weight on direct material gains. Consequently, the fraction of highly prosocial individuals will be substantially smaller in the group of voluntary participants than in the group of involuntary participants. Laboratory or field experiments with voluntary participation that aim to test prosocial behavior are therefore likely to underestimate prosocial behavior. In market environments agents can often avoid situations where they must make costly contributions to signal their generosity. This explains why prosocial behavior is observed less frequently in market environments. At a more general level our message is that both in laboratory and field experiments we should worry as much about problems related to self-selection of participants as in non-experimental

\footnotetext{
${ }^{9}$ There exist some anecdotical evidence for this. The marketing department of NH-hoteles received an email of someone who liked the promotion but wrote that he would feel very uncomfortable to pay less than 50 euro for a stay and therefore decided not to participate.
} 
studies.

\section{References}

[1] Ariely, D., B. Kőszegi, N. Mazar and K. Shampan'er (2004), Price-sensitive preferences, mimeo Berkeley.

[2] Azar, O.H. (2003), The Implications of Tipping for Economics and Management, International Journal of Social Economics 30, 1084-1094.

[3] Bardsley, N. (2005), Altruism or Artefact? A note on Dictator Game Giving: mimeo Nottingham University.

[4] Bateson, M., D. Nettle and G. Roberts (2006), Cues of being watched enhance cooperation in a real-world setting, Biology Letters (doi:10.1098/rsbl.2006.0509).

[5] BÉnabou, R. And J. Tirole (2006), Incentives and prosocial behavior, American Economic Review, forthcoming.

[6] Camerer, C.F. (2003), Behavioral game theory: Experiments in strategic interaction, New York: Russel Sage Foundation.

[7] Camerer, C.F., G. Loewenstein and M. Rabin (2003), Advances in Behavioral Economics, Princeton University Press.

[8] FAlk, A. (2004), Charitable giving as a gift exchange: Evidence from a field experiment, IZA DP 1148.

[9] Fehr, E., G. Kirchsteiger And A. Riedl (1998), Gift exchange and reciprocity in competitive experimental markets, European Economic Review 42, 1-34.

[10] Gneezy, U. And J.A. List (2006), Putting behavioral economics to work: Testing for gift exchange in labor markets using field experiments, Econometrica 74, 1365-1384.

[11] Harrison, G. And J.A. List (2004) Field Experiments, Journal of Economic Literature XLII, 1009-1055.

[12] Kalman, P.J. (1968), Theory of consumer behavior when prices enter the utility function, Econometrica 36, 497-510.

[13] Kahneman, D. And A. Tversky (1979), Prospect theory: An analysis of decision under risk, Econometrica 47, 263-291. 
[14] Köszegi, B. And M. RABIn (2006), A model of reference-dependent preferences, Quarterly Journal of Economics, forthcoming.

[15] Lazear, E., U. Malmendier and R. Weber (2005), Sorting in Experiments, Mimeo Stanford business school.

[16] List, J., And S. LevitT (2005), What do Laboratory Experiments Tell us about the Real World?, Unpublished manuscript Chicago.

[17] Milinsky, M., D. Semmann and H.J. Krambeck (2002), Reputation helps solve the tragedy of the commons, Nature 393, 573-577.

[18] Ruffle, B.J. (1996), More is better, but fair is fair: tipping in dictator and ultimatum games, Games and Economic Behavior 23, 247-265.

[19] Soetevent, A.R. (2005), Anonymity in giving in a natural context-a field experiment in 30 churches, Journal of Public Economics 89, 2301-2323. 


\begin{tabular}{lcc}
\hline \hline & Regular guests & Experiment guests \\
\hline Observations & 301 & 4721 \\
Donations (euro) & 48.75 & 24.41 \\
Paid nothing & $8.0 \%$ & $14.4 \%$ \\
Paid less than 10\% & $13.0 \%$ & $27.0 \%$ \\
Paid more than 90\% & $12.3 \%$ & $1.0 \%$ \\
3-star hotel & $50.8 \%$ & $46.0 \%$ \\
4-star hotel & $36.9 \%$ & $35.8 \%$ \\
5-star hotel & $12.3 \%$ & $18.2 \%$ \\
Hotel grade & & \\
& 7.35 & 7.26 \\
Female & $30.6 \%$ & $44.2 \%$ \\
Age & 39.5 & 33.1 \\
Belgium & & \\
Dutch & $9.6 \%$ & $10.8 \%$ \\
Often in hotels & $58.8 \%$ & $87.0 \%$ \\
Many comments & $45.8 \%$ & $25.4 \%$ \\
\hline \hline
\end{tabular}

Table 1: Summary statistics 


\begin{tabular}{lcc}
\hline \hline Regular guest & $18.088^{* *}(1.302)$ \\
Posted price & 0.035 & $(0.032)$ \\
Female & $-1.469^{* *}(0.572)$ \\
Age/10 & $7.566^{* *}(1.341)$ \\
Age squared/100 & $-0.466^{* *}(0.166)$ \\
Belgium & $-8.630^{* *}(1.772)$ \\
Dutch & $-11.184^{* *}(1.559)$ \\
Often in hotels & $0.218 \quad(0.648)$ \\
& \\
Fixed hotel effects & yes \\
Sample size & 5022 \\
\hline \hline
\end{tabular}

Note: ${ }^{*}$ significant at $10 \%$ and ${ }^{* *}$ significant at $5 \%$.

Table 2: Price paid. 


\begin{tabular}{|c|c|c|c|c|c|c|c|}
\hline & (1) & $(2$ & & (3) & & \multicolumn{2}{|c|}{$(4)$} \\
\hline Posted price & $0.658^{* *}(0.206)$ & $0.566^{* *}$ & * $(0.204)$ & $0.595^{* *}$ & $(0.202)$ & $0.475^{* *}$ & $(0.223)$ \\
\hline Female & & 1.767 & $(4.279)$ & 0.609 & $(4.237)$ & 1.131 & $(4.583)$ \\
\hline Age/10 & & $13.145^{*}$ & $(7.876)$ & 9.509 & $(7.863)$ & 7.768 & $(9.421)$ \\
\hline Age squared/100 & & -0.877 & $(0.894)$ & -0.603 & $(0.886)$ & -0.336 & $(1.062)$ \\
\hline Belgium & & -9.972 & $(7.771)$ & -11.285 & $(7.674)$ & -11.805 & $(8.570)$ \\
\hline Dutch & & $-10.759^{* *}$ & * $(4.711)$ & $-12.421^{* *}$ & $(4.679)$ & $-11.557^{* *}$ & $(5.171)$ \\
\hline Often in hotels & & 0.691 & $(3.900)$ & 1.761 & $(3.862)$ & 2.679 & $(4.366)$ \\
\hline Hotel grade & & & & $4.687^{* *}$ & $(1.602)$ & & \\
\hline Personnel good & & & & & & 1.708 & $(15.423)$ \\
\hline Personnel very good & & & & & & -2.724 & $(16.213)$ \\
\hline Room good & & & & & & 8.297 & $(6.778)$ \\
\hline Room very good & & & & & & 12.389 & $(8.477)$ \\
\hline Breakfast good & & & & & & 6.927 & $(7.439)$ \\
\hline Breakfast very good & & & & & & 6.731 & $(8.382)$ \\
\hline Fixed hotel effects & yes & ye & & yes & & yes & \\
\hline Sample size & 301 & 30 & & 301 & & 26 & \\
\hline
\end{tabular}

Note: ${ }^{*}$ significant at $10 \%$ and ${ }^{* *}$ significant at $5 \%$.

Table 3: Price paid of regular guests.

\begin{tabular}{|c|c|c|c|c|c|c|}
\hline & \multicolumn{2}{|c|}{$(1)$} & \multicolumn{2}{|c|}{ (2) } & $(3)$ & $(4)$ \\
\hline Posted price & 0.010 & $(0.033)$ & 0.004 & $(0.032)$ & $0.009 \quad(0.032)$ & $0.015 \quad(0.034)$ \\
\hline Female & & & $-1.586^{* *}$ & (0.559) & $-1.728^{* *}(0.557)$ & $-1.992^{* *}(0.582)$ \\
\hline Age/10 & & & $0.749^{* *}$ & ${ }^{*}(0.134)$ & $7.829^{* *}(1.337)$ & $7.246^{* *}(1.388)$ \\
\hline Age squared/100 & & & $-0.481^{* *}$ & $(0.167)$ & $-0.551^{* *}(0.166)$ & $-0.485^{* *}(0.172)$ \\
\hline Belgium & & & $-6.694^{* *}$ & ${ }^{k}(2.058)$ & $-6.725^{* *}(2.049)$ & $-3.827^{*} \quad(2.187)$ \\
\hline Dutch & & & $-9.037^{* *}$ & ${ }^{*}(1.885)$ & $-8.959^{* *}(1.877)$ & $-6.287^{* *}(2.028)$ \\
\hline Often in hotels & & & 0.091 & $(0.642)$ & $0.506 \quad(0.643)$ & $0.709 \quad(0.676)$ \\
\hline Hotel grade & & & & & $1.671^{* *}(0.259)$ & \\
\hline Personnel good & & & & & & $4.163^{* *}(1.481)$ \\
\hline Personnel very good & & & & & & $2.099 \quad(1.605)$ \\
\hline Room good & & & & & & $3.048^{* *}(0.811)$ \\
\hline Room very good & & & & & & $3.718^{* *}(1.119)$ \\
\hline Breakfast good & & & & & & $2.421^{* *}(1.216)$ \\
\hline Breakfast very good & & & & & & $2.985^{* *}(1.322)$ \\
\hline Fixed hotel effects & & yes & ye & es & yes & yes \\
\hline Sample size & & 1721 & 472 & 21 & 4721 & 4337 \\
\hline
\end{tabular}

Note: * significant at $10 \%$ and ${ }^{* *}$ significant at $5 \%$.

Table 4: Price paid of experiment guests. 


\begin{tabular}{lr}
\hline \hline Regular guest & $0.154^{* *}(0.070)$ \\
Posted price & $-0.003^{*}(0.002)$ \\
Female & $0.090^{* *}(0.031)$ \\
Age $/ 10$ & $-0.145^{* *}(0.072)$ \\
Age squared $/ 100$ & $0.035^{* *}(0.009)$ \\
Belgium & $0.218^{* *}(0.096)$ \\
Dutch & $0.149^{*}(0.084)$ \\
Often in hotels & $-0.249^{* *}(0.035)$ \\
& \\
Fixed hotel effects & yes \\
Sample size & 5022 \\
\hline \hline
\end{tabular}

Note: ${ }^{*}$ significant at $10 \%$ and ${ }^{* *}$ significant at $5 \%$.

Table 5: Hotel grades. 


\begin{tabular}{|c|c|c|c|c|c|c|}
\hline & \multicolumn{2}{|c|}{ (1) } & \multicolumn{2}{|c|}{$(2)$} & \multicolumn{2}{|c|}{ (3) } \\
\hline Posted price & -0.006 & $(0.008)$ & -0.006 & $(0.008)$ & -0.009 & $(0.006)$ \\
\hline Female & & & 0.247 & $(0.163)$ & 0.138 & (0.117) \\
\hline Age/10 & & & $0.776^{* *}$ & $(0.300)$ & 0.237 & $(0.240)$ \\
\hline Age squared/100 & & & $-0.059^{*}$ & $(0.034)$ & -0.013 & $(0.027)$ \\
\hline Belgium & & & 0.280 & $(0.296)$ & -0.155 & $(0.218)$ \\
\hline Dutch & & & $0.355^{*}$ & $(0.179)$ & 0.224 & $(0.132)$ \\
\hline Often in hotels & & & -0.228 & $(0.149)$ & -0.075 & $(0.111)$ \\
\hline Personnel good & & & & & $1.336^{* *}$ & $(0.393)$ \\
\hline Personnel very good & & & & & $1.724^{* *}$ & $(0.413)$ \\
\hline Room good & & & & & $1.324^{* *}$ & $(0.173)$ \\
\hline Room very good & & & & & $2.000^{* *}$ & $(0.216)$ \\
\hline Breakfast good & & & & & $0.673^{* *}$ & $(0.190)$ \\
\hline Breakfast very good & & & & & $0.982^{* *}$ & $(0.214)$ \\
\hline Fixed hotel effects & & es & ye & & ye & \\
\hline Sample size & & 1 & 30 & & 26 & \\
\hline
\end{tabular}

Note: ${ }^{*}$ significant at $10 \%$ and ${ }^{* *}$ significant at $5 \%$.

Table 6: Hotel grades of regular guests.

\begin{tabular}{|c|c|c|c|}
\hline & (1) & (2) & (3) \\
\hline Posted price & $-0.003^{*} \quad(0.002)$ & $-0.003 \quad(0.002)$ & $0.001 \quad(0.002)$ \\
\hline Female & & $0.085^{* *}(0.031)$ & $(0.024)$ \\
\hline Age/10 & & $-0.204^{* *}(0.075)$ & $-0.180^{* *}(0.057)$ \\
\hline Age squared/100 & & $0.042^{* *}(0.009)$ & $-0.027^{* *}(0.007)$ \\
\hline Belgium & & $0.018 \quad(0.116)$ & $0.068 \quad(0.090)$ \\
\hline Dutch & & -0.047 & $0.149^{*} \quad(0.084)$ \\
\hline Often in hotels & & $-0.248^{* *}(0.036)$ & $-0.105^{* *}(0.028)$ \\
\hline Personnel good & & & $0.813^{* *}(0.061)$ \\
\hline Personnel very good & & & $1.138^{* *}(0.066)$ \\
\hline Room good & & & $1.058^{* *}(0.033)$ \\
\hline Room very good & & & $1.708^{* *}(0.046)$ \\
\hline Breakfast good & & & $0.593^{* *}(0.050)$ \\
\hline Breakfast very good & & & $0.967^{* *}(0.054)$ \\
\hline Fixed hotel effects & yes & yes & yes \\
\hline Sample size & 4721 & 4721 & 4337 \\
\hline
\end{tabular}

Note: ${ }^{*}$ significant at $10 \%$ and ${ }^{* *}$ significant at $5 \%$.

Table 7: Hotel grades of experiment guests. 


\begin{tabular}{|c|c|c|c|c|c|c|c|c|}
\hline & \multicolumn{2}{|c|}{$(1)$} & \multicolumn{2}{|c|}{$(2)$} & \multicolumn{2}{|c|}{$(3)$} & \multicolumn{2}{|c|}{ (4) } \\
\hline Posted price & 0.000 & $(0.003)$ & 0.000 & $(0.003)$ & 0.000 & $(0.003)$ & -0.000 & $(0.003)$ \\
\hline Female & 0.042 & $(0.069)$ & 0.061 & $(0.069)$ & 0.042 & $(0.069)$ & 0.061 & $(0.069)$ \\
\hline Age/10 & -0.129 & $(0.127)$ & -0.083 & $(0.126)$ & -0.133 & $(0.128)$ & -0.091 & $(0.127)$ \\
\hline Age squared/100 & 0.013 & $(0.014)$ & 0.010 & $(0.014)$ & 0.013 & $(0.014)$ & 0.010 & $(0.014)$ \\
\hline Belgium & 0.082 & $(0.123)$ & 0.102 & $(0.122)$ & 0.085 & $(0.124)$ & 0.111 & $(0.122)$ \\
\hline Dutch & 0.086 & $(0.077)$ & 0.110 & $(0.076)$ & 0.090 & $(0.078)$ & 0.120 & $(0.077)$ \\
\hline Often in hotels & -0.002 & $(0.063)$ & -0.009 & $(0.062)$ & -0.003 & $(0.063)$ & -0.010 & $(0.062)$ \\
\hline Hotel grade & & & $-0.078^{* *}$ & $(0.027)$ & & & $-0.081^{* *}$ & $(0.028)$ \\
\hline Donation & & & & & 0.000 & $(0.001)$ & 0.001 & $(0.001)$ \\
\hline Fixed hotel effects & \multicolumn{2}{|c|}{ yes } & \multicolumn{2}{|c|}{ yes } & \multicolumn{2}{|c|}{ yes } & \multicolumn{2}{|c|}{ yes } \\
\hline Sample size & \multicolumn{2}{|c|}{288} & \multicolumn{2}{|c|}{288} & \multicolumn{2}{|c|}{288} & \multicolumn{2}{|c|}{288} \\
\hline
\end{tabular}

Note: ${ }^{*}$ significant at $10 \%$ and ${ }^{* *}$ significant at $5 \%$.

Table 8: Writing many comments of regular guests.

\begin{tabular}{|c|c|c|c|c|}
\hline & (1) & (2) & (3) & (4) \\
\hline Posted price & $\begin{array}{ll}-0.000 \quad(0.001)\end{array}$ & $\begin{array}{ll}-0.001 \quad(0.001)\end{array}$ & $-0.000 \quad(0.001)$ & $-0.001 \quad(0.001)$ \\
\hline Female & $0.025^{*} \quad(0.015)$ & $0.035^{* *}(0.014)$ & $0.025^{*} \quad(0.015)$ & $0.036^{* *}(0.014)$ \\
\hline Age/10 & $0.216^{* *}(0.035)$ & $0.196^{* *}(0.034)$ & $0.217^{* *}(0.035)$ & $0.193^{* *}(0.035)$ \\
\hline Age squared/100 & $-0.025^{* *}(0.004)$ & $-0.020^{* *}(0.004)$ & $-0.025^{* *}(0.004)$ & $-0.020^{* *}(0.004)$ \\
\hline Belgium & $0.077 \quad(0.056)$ & $0.087 \quad(0.055)$ & $0.077 \quad(0.056)$ & $0.089 \quad(0.055)$ \\
\hline Dutch & $0.105^{* *}(0.052)$ & $0.109^{* *}(0.050)$ & $0.104^{* *}(0.052)$ & $0.112^{* *}(0.051)$ \\
\hline Often in hotels & $0.054^{* *}(0.017)$ & $0.027 \quad(0.017)$ & $0.054^{* *}(0.017)$ & $0.027 \quad(0.017)$ \\
\hline Hotel grade & & $-0.106^{* *}(0.007)$ & & $-0.107^{* *}(0.007)$ \\
\hline Donation & & & -0.000 & $0.000 \quad(0.001)$ \\
\hline Fixed hotel effects & yes & yes & yes & yes \\
\hline Sample size & 4550 & 4550 & 4550 & 4550 \\
\hline
\end{tabular}

Note: ${ }^{*}$ significant at $10 \%$ and ${ }^{*}$ significant at $5 \%$.

Table 9: Writing many comments of experiment guests. 


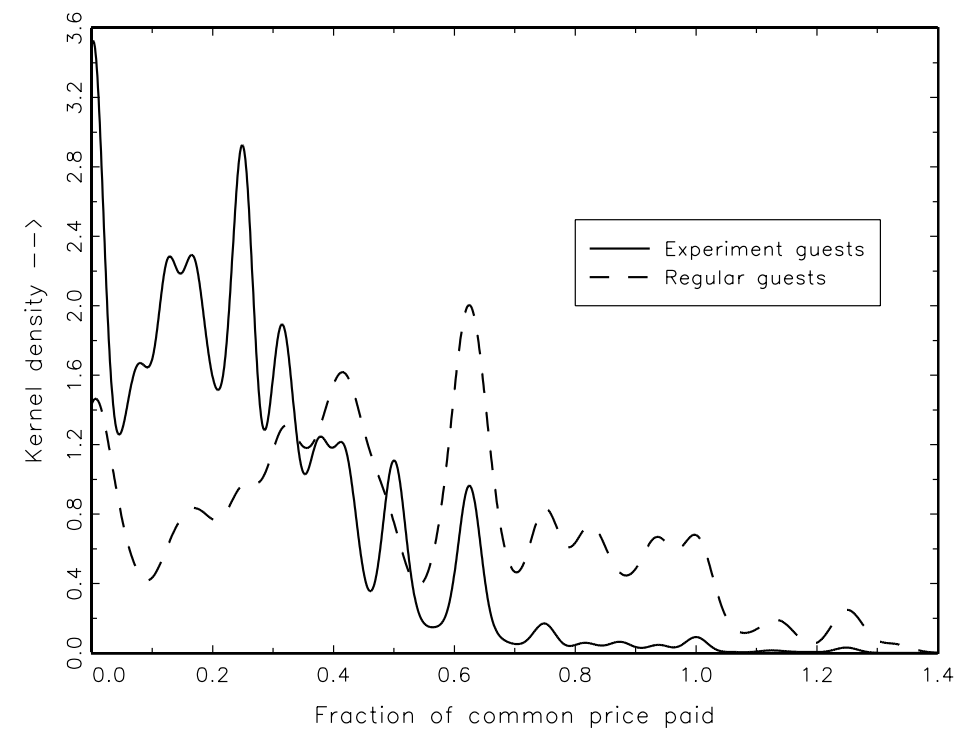

Figure 1: Kernel density estimation of the payments of regular and experiment guests as fraction of the usual hotel price.

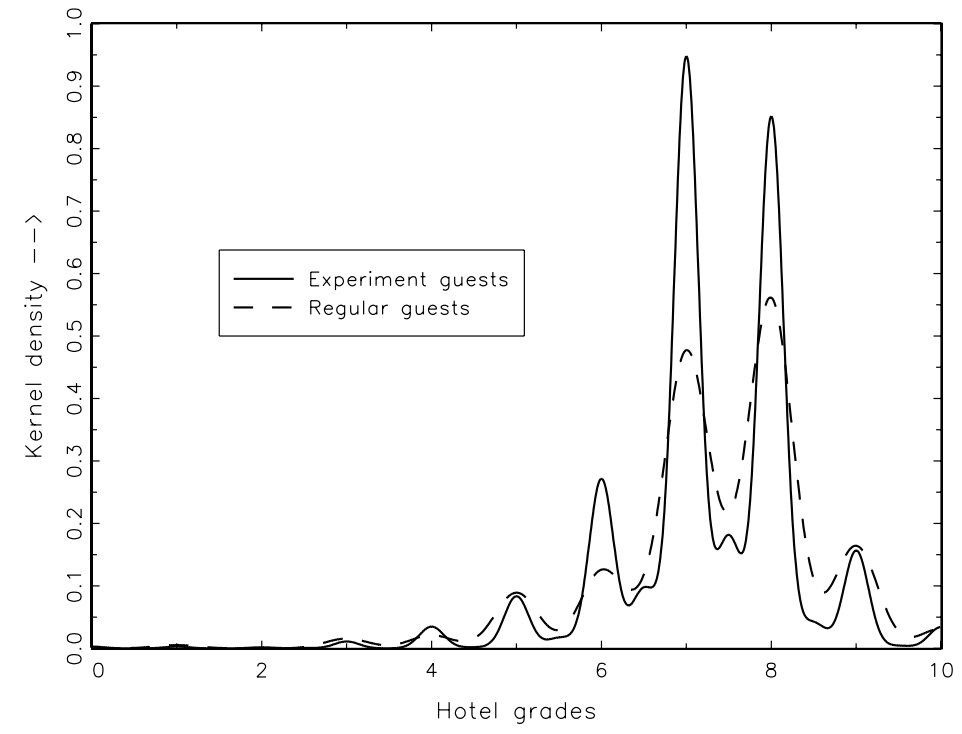

Figure 2: Kernel density estimation of the hotel grades given by regular and experiment guests. 
Appendix: Questionnaire filled in at check-out.

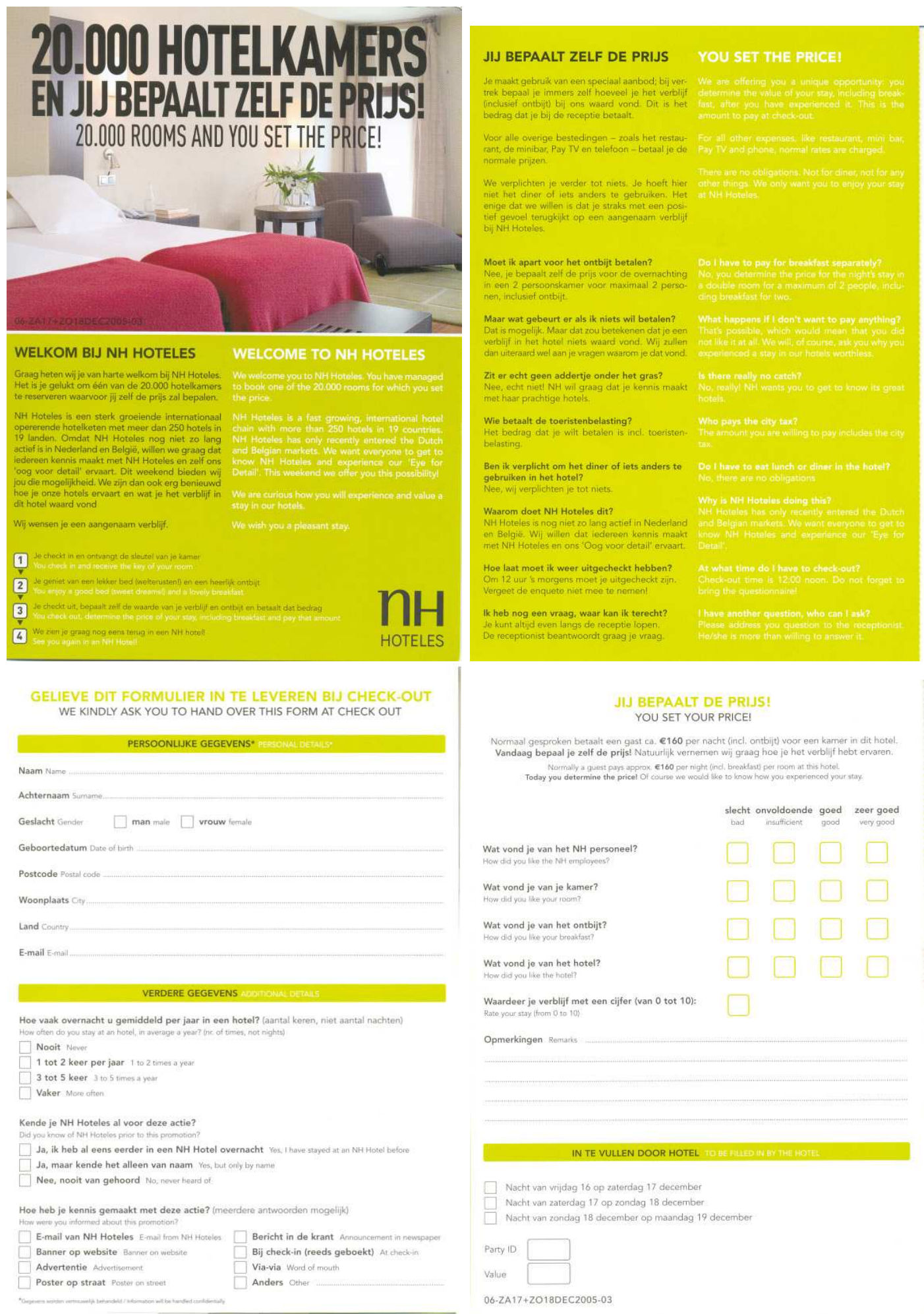

